\title{
Laboratory Quality Audit in 25 Anti-Retroviral Therapy Facilities in North West of Nigeria
}

\author{
Feyisayo Ebenezer Jegede, Henry Akwen Mbah*, Timothy Nathaniel Yakubu, \\ Oluwasanmi Adedokun, Olubunmi Ruth Negedu-Momoh, Kwasi Torpey \\ Family Health International (FHI360), Abuja, Nigeria \\ Email: ${ }^{*}$ mmbah@ng.fhi360.org
}

Received 28 August 2014; revised 28 September 2014; accepted 28 October 2014

Copyright (C) 2014 by authors and Scientific Research Publishing Inc.

This work is licensed under the Creative Commons Attribution International License (CC BY). http://creativecommons.org/licenses/by/4.0/

\section{Abstract}

Introduction: A laboratory's ability to consistently produce high-quality and reliable results hinges on adopting laboratory standards that guide daily practices to ensure steady quality improvement. Although assessment is an extremely rewarding exercise in health care quality improvement processes, it is always considered very time consuming and expensive in developing world settings. A quarterly internal audit was conducted in 25 FHI360 supported Antiretroviral Treatment laboratories in the North West of Nigeria which can surely provide reference for other countries. Methodology: A checklist adapted from the World Health Organization/African Regional Office laboratory accreditation checklist was used to quantitatively evaluate 7 quality essentials (QEs). A team composed of technical staff from FHI360, State Ministry of Health and facility laboratory heads, conducted the audits, developed and monitored intervention plans. Information obtained with the checklist was captured in excel, validated and imported into Grappa Prism software version 5.0 for analysis. Results: Most (92\%) facilities were at secondary level with (8\%) at tertiary level. The mean total score on all QEs across the facilities was $63.34 \pm 9.77$ in quarter (Q) $1,68.8 \pm$ 10.91 in $Q 2,72.59 \pm 8.02$ in $Q 3$ and $72.72 \pm 9.16$ in $Q 4(p \leq 0.0001)$. The most improved $Q E$ through Q1-Q4 was organization and personnel $(32.2 \%)$, while signage/bench top reference had an $18.6 \%$ point decline. In ranking facilities based on differences of total scores between Q4 and Q1, Kachia General Hospital was the highest with 27 point increase. Considering the mean percentage score for all quarters per facility, 4 had $\geq 80 \%, 19$ had between $60 \%-80 \%$ and 2 had $<60 \%$. The total non-conformities cited for QI-Q4 were 185, 100, 78 and 64 respectively with highest recorded in internal and external quality control and the least in facility and safety. Conclusion: We recorded some improvement in most QEs confirming the benefits of internal audits, reviews and follow-up. However, much more is needed in terms of technical assistance, capacity building, mentorship, and commitment at facility and state level to meet minimum acceptable laboratory quality stan-

\footnotetext{
*Corresponding author.
}

How to cite this paper: Jegede, F.E., Mbah, H.A., Yakubu, T.N., Adedokun, O., Negedu-Momoh, O.R. and Torpey, K. (2014) Laboratory Quality Audit in 25 Anti-Retroviral Therapy Facilities in North West of Nigeria. Open Journal of Clinical Diagnostics, 4, 193-204. http://dx.doi.org/10.4236/ojcd.2014.44028 
dards.

Keywords

Laboratory, Internal Audits, Quality Essentials, Non-Conformities, Nigeria

\section{Introduction}

Modern medical practice is increasingly dependent on reliable clinical laboratory services [1]. Yet in Nigeria, clinical laboratories are grossly inadequate with weak infrastructure [2] and Quality Management Systems (QMS) are uncommon like in other developing countries [3] [4]. Many laboratories are faced with numerous challenges including improper record keeping, documentation of procedures and lack of internal auditing. Family Health International (FHI) 360 with funding from the President’s Emergency Plan for AIDS Relief (PEPFAR) through United State of Agency for International Development (USAID) and Global Fund to fight AIDS and Tuberculosis and Malaria (GFATM) supported the Government of Nigeria to strengthen laboratories in 26 Public Health facilities in North West region of Nigeria for comprehensive Antiretroviral therapy (ART) services from 2005 to 2012. The key activities and support provided to strengthen the laboratories include, renovation of infrastructure, provision of alternate power sources and running water, procurement and installation of equipment, training of human resource, supply of commodities and reinforcement of the supply chain and logistics management systems. Others include establishment of the culture of planned preventive maintenance (PPM), introduction of laboratory quality management systems, registration for proficiency testing programs, development of policies, SOP, job aids, reporting and monitoring tools as well as improvement of information management, regular on-site technical assistance, monitoring and mentoring.

Although these interventions led to improved laboratory services, there was no standardized form of laboratory audit in place to accurately measure the level of improvement. The only form of assessment in place was Data Quality Assurance (DQA). However, the DQA simply checks for consistencies in results generated by the laboratory and its transcription into various forms and registers used for documentation. The main objective of DQA was to guide against transcriptional error and to ensure that the right result for the right patient is transmitted to the users and captured on the project's electronic database, the District Health Information System (DHIS). Thus, there was limited focus on the processes to ensure accuracy and reliability of the laboratory test results.

Providing quality laboratory test results that are accurate, reliable, and reproducible will most effectively come through adopting laboratory standards that guide daily laboratory practices and institute a framework for quality management at the facility and network levels [5].

There is the need for these laboratories to institute periodic and systematic assessments like internal audits [6] to improve important functions, work processes and their outcomes [7], so as to ensure quality standards, generate reliable results and guarantee patient safety. Audits assess actual against expectation and provide feedback to staff and users thus creating room for continuous quality improvement for patient safety and laboratory efficiency.

Constraints faced by poor countries call for innovative approaches [8] [9] that would guarantee the minimum acceptable quality in laboratory processes while striving to meet the highest standards such as International Organization for Standardization (ISO)-15189 [10] for medical laboratories. In resource-limited setting, it may be justifiable to develop and use 'fit for purpose' local quality standards based on internationally recognized laboratory quality management frameworks or protocols [6] [11] [12]. In line with this, World Health Organization, Regional Office for Africa (WHO-AFRO) in collaboration with other stakeholders developed and launched a novel laboratory accreditation approach in Kigali, Rwanda in 2009 [13]. This effort led to the Strengthening Laboratory Management towards Accreditation (SLMTA) training program [8], and Stepwise Laboratory (Quality) Improvement Process towards Accreditation (SLIPTA) tools [9]. Member states were encouraged to implement this novel approach to ensure quality improvement in laboratory services. Due to limited in-country technical capacity and resources to roll out the WHO-AFRO laboratory accreditation standards, it was piloted only in Infectious Disease Hospital (IDH) Kano. One of FHI360 supported health facilities in North Western Nigeria. Access to services with the highest standard possible remains the major focus in FHI360 ART program imple- 
mentation.

Although assessment is an extremely rewarding exercise in health care quality improvement processes, it is always considered a very time-consuming and expensive process in developing world settings. Thus, FHI360 developed a simple internal audit checklist to mirror the WHO-AFRO standard which could be easily administered. As part of routine program implementation process, periodic internal audit was undertaken in the 25 ART laboratories in North West Nigeria to identify gaps with the view of recommending appropriate interventions and action plan to address the gaps and monitor improvements overtime. Here we present the findings and discuss on the challenges faced in the field.

\section{Methodology}

\subsection{Project Design and Setting}

This was a quantitative longitudinal audit of laboratory quality systems. The audit was done quarterly as routine process in ART sites supported by FHI360 in seven states in North West region of Nigeria (Table 1).

Table 1. CD4+ tests done and ART patient enrollments figure at FHI360 supported sites in North West region of Nigeria as at March 2013.

\begin{tabular}{|c|c|c|c|c|c|}
\hline SN & Facility Name & State & Level of Care & Total CD4+ Test Done & $\begin{array}{c}\text { Total Number of Patients on } \\
\text { ART }\end{array}$ \\
\hline 1 & Infectious Disease Hospital Kano* & Kano & Secondary & 14,576 & 12,524 \\
\hline 2 & $\begin{array}{c}\text { Murtala Mohammed Specialist } \\
\text { Hospital Kano }\end{array}$ & Kano & Secondary & 13,834 & 7631 \\
\hline 3 & HasiyaBayeroPeadiatric Hospital Kano & Kano & Secondary & 3600 & 3591 \\
\hline 4 & $\begin{array}{c}\text { Sir Mohammed Sanusi Specialist Hospital } \\
\text { Kano }\end{array}$ & Kano & Secondary & 4369 & 4197 \\
\hline 5 & Wudil GH & Kano & Secondary & 2344 & 2007 \\
\hline 6 & Gumel GH & Jigawa & Secondary & 1849 & 1590 \\
\hline 7 & Katsina GH & Katsina & Secondary & 8940 & 7664 \\
\hline 8 & Funtua GH & Katsina & Secondary & 5887 & 7723 \\
\hline 9 & Daura GH & Katsina & Secondary & 2062 & 2578 \\
\hline 10 & Dutsin Ma GH & Katsina & Secondary & 1008 & 1000 \\
\hline 11 & Kachia GH & Kaduna & Secondary & 2193 & 2106 \\
\hline 12 & ZongoKataf GH & Kaduna & Secondary & 2598 & 1636 \\
\hline 13 & BirninGwari GH & Kaduna & Secondary & 1850 & 1198 \\
\hline 14 & Ikara GH & Kaduna & Secondary & 1887 & 1005 \\
\hline 15 & FMCGusua & Zamfara & Tertiary & 4861 & 4289 \\
\hline 16 & Shinkafi GH & Zamfara & Secondary & 312 & 337 \\
\hline 17 & TalataMafara GH & Zamfara & Secondary & 1121 & 957 \\
\hline 18 & KauraNamoda GH & Zamfara & Secondary & 1214 & 917 \\
\hline 19 & Sokoto Specialist Hospital & Sokoto & Secondary & 8684 & 5250 \\
\hline 20 & DogoDagi GH & Sokoto & Secondary & 114 & 352 \\
\hline 21 & Tambuwal GH & Sokoto & Secondary & 571 & 544 \\
\hline 22 & Illela GH & Sokoto & Secondary & 1214 & 1244 \\
\hline 23 & Federal Medical Center Kebbi & Kebbi & Tertiary & 2689 & 1962 \\
\hline 24 & Sir Yahaya Specialist Hospital & Kebbi & Secondary & 3334 & 3196 \\
\hline 25 & Yauri GH & Kebbi & Secondary & 1370 & 2176 \\
\hline 26 & Zuru GH & Kebbi & Secondary & 2662 & 3972 \\
\hline
\end{tabular}

*IDH Kano was involved in the pilot phase of WHO/AFRO laboratory accreditation process and not part of these audits. GH: General Hospital, FMC: Federal Medical Center. 


\subsection{Assessment Tool}

On-site monitoring checklist was developed to mirror the WHO/AFRO SLIPTA check list [14]. The 12 Quality essentials (QEs) were compressed to seven composite quality management elements to suit the current practice and to make it simple and easy to administer. The quality management elements with various percentage weighting that were considered are: 1) Documents and records (10\%); 2) Organization and personnel (10\%); 3) Internal and external quality control (21\%); 4) Inventory control system (10\%); 5) Equipment (10\%); 6) Signage/bench top references (17\%); and 7) Facility and safety (22\%). The modified assessment check list consists of a total of 46 (yes/no/ partial) questions. Full points are awarded if all requirement were fulfilled and partial when some requirements are not fulfilled and no point when all requirements not fulfilled.

\subsection{Assessment}

This quantitative audit was carried out quarterly between January to December 2012 for various laboratory quality management elements. Marks were awarded based on direct observation, review of records and documents, direct open-ended question techniques to staff or combination of all in some cases. The audit was carried out by FHI360 laboratory technical officers, facility heads of laboratory departments and State Implementation Team (SIT) laboratory focal persons. These focal persons are government staff from respective State Ministries of Health providing support to these laboratories as part of FHI360's capacity building, sustainability and ownership strategy. The team was trained on the use of the audit tool however FHI360 laboratory technical officers participate in the audits, and also review audit reports conducted by SIT laboratory focal persons and seek clarification where applicable. Nonfulfillment of specific requirements per QE were outlined as non -conformities (NCs). The sum of a particular NC per quarter was derived by counting the number of facilities not meeting a particular requirement of the QE in each quarter. At the end of the assessment, summary of findings and observed NCs were reviewed with facility staff and a joint action plan to address such deficiencies was drafted. An example is shown in Table 2. Following an audit, a laboratory overall quality score of above $80 \%$ denotes good quality management system and such laboratories were encouraged to maintain continuous quality improvement. Laboratories with a score of $60 \%$ - $80 \%$, were required to address all observed NCs within 30 days, while those that scored less than $60 \%$ required an urgent intervention to address observed NCs

\subsection{Data Collection, Management and Analysis}

We used the adapted checklist to capture data manually at sites. Data was entered into Microsoft Excel worksheets at FHI360 Kano office, cleaned, validated and sent to FHI360 country office for analysis. Data was imported into GraphPad Prism software version 5.0 (GraphPad Software, Inc., CA, USA) for analysis. Facilities were ranked on the basis of difference between total score for all quality essentials between quarter 4 and quarter 1. Quality essential scores were expressed as percentages to show the most improved quality essentials. Repeated measures analysis of variance (ANOVA) was used to compare quality essential scores by facility across all four quarters. A p-value of 0.05 was considered significant for all analysis.

\section{Results}

A total of 25 health facilities were assessed. Four (16\%) facilities were located in each of Kano, Kaduna, Katsina, Kebbi, Sokoto and Zamfara states with one (4\%) in Jigawa state. Twenty three (92\%) were secondary health facilities while two (8\%) were tertiary health facilities (Table 1).

In ranking facilities based on differences of total scores between quarter 4 (Q4) and quarter 1(Q1), Kachia General Hospital, Kaduna showed the highest increment with a 27 point increase. In all 18 (72\%) facilities showed improved performance over four quarters. Seven (28\%) facilities had a decrease at quarter 4 compared to quarter 1 (Table 3).

On analyzing the overall mean score for all quarters across facilities, only four (16\%) facilities scored 80\% and above while majority 19 (76\%) scored between $60 \%-79 \%$ and 2 (8\%) of the facilities scored less than 60\%. Kaura Namoda General Hospital Zamfara had highest overall average score of 83\% (81.5 Q1: 81 Q2: 83.5 Q3: Q4 86.5\%), while the least average scores was 59\% Q1 46; Q2 46; Q3 79; Q4 65.5) (Table 3)

\section{QE Percentage, Mean Score and Non-Conformities}

The percentage score for each QE was determined through the four quarters, was calculated to see the trend in 
Table 2. A typical summary of audit findings (non-conformities) and planned interventions.

\begin{tabular}{|c|c|c|}
\hline Quality essentials & Summary of findings & Planned intervention to address identified gaps \\
\hline $\begin{array}{l}\text { Document and } \\
\text { record }\end{array}$ & $\begin{array}{l}\text { - SOPS not signed by relevant personnel. } \\
\text { - General Laboratory Register and Work sheet not } \\
\text { updated }\end{array}$ & $\begin{array}{l}\text { - Mentored HOD and relevant Lab staff to review and } \\
\text { sign SOPs and update outstanding documents }\end{array}$ \\
\hline $\begin{array}{l}\text { Organization and } \\
\text { personnel }\end{array}$ & $\begin{array}{l}\text { - Organizational chart describing hierarchical } \\
\text { relationships of staff not available. } \\
\text { - Personnel folders do not containing relevant } \\
\text { certificates and training records of staff such as } \\
\text { license, Job description ,training and competency etc. }\end{array}$ & $\begin{array}{l}\text { - Supported HOD to design an organogram and each } \\
\text { staff encouraged to populate folders with relevant } \\
\text { documents }\end{array}$ \\
\hline $\begin{array}{l}\text { Internal and/ } \\
\text { external quality } \\
\text { control }\end{array}$ & $\begin{array}{l}\text { - } \quad \text { L-J Charts for IQC runs not plotted } \\
\text { - } \quad \text { EQC and IQC records not reviewed by designated } \\
\text { officers } \\
\text { Records of poor EQC/IQC performance not } \\
\text { adequately documented in CAPA } \\
\text { - } \quad \text { Laboratory internal audit not done } \\
\text { - Not registered for at least one EQC Scheme }\end{array}$ & $\begin{array}{l}\text { - Conducted on-site coaching and mentoring on IQC } \\
\text { and EQC documentation. } \\
\text { - Provided CAPA form to capture incidence and } \\
\text { occurrence } \\
\text { - Conducted step-down training on the principle of } \\
\text { internal auditing and provided the necessary tools } \\
\text { - Registered site for at least CD4+ EQC scheme }\end{array}$ \\
\hline $\begin{array}{l}\text { Inventory control } \\
\text { system }\end{array}$ & $\begin{array}{l}\text { - Tally card not updated } \\
\text { - Ambient temperature and refrigerator not properly } \\
\text { monitored } \\
\text { - Broken thermometer }\end{array}$ & $\begin{array}{l}\text { - Verified and updated tally cards to account for } \\
\text { reagents/consumables } \\
\text { - Provided tools to monitor and record temperature } \\
\text { and updated missing information } \\
\text { - Provided new thermometer }\end{array}$ \\
\hline Equipment & $\begin{array}{l}\text { - Operator's equipment maintenance charts not up to } \\
\text { date and not reviewed by supervisor } \\
\text { - Faulty equipment due to rat infestation } \\
\text { - Equipment not covered when not in use } \\
\text { - Faulty air conditioner }\end{array}$ & $\begin{array}{l}\text { - Strengthened capacity to document daily } \\
\text { maintenance activity and provide tools } \\
\text { - Faulty equipment and air conditioner were repaired } \\
\text { or replaced } \\
\text { - Fumigation was done and regular schedule } \\
\text { established } \\
\text { - Sample referral was institutionalized and } \\
\text { strengthened and local biomedical engineers were } \\
\text { trained to carry out minor repairs }\end{array}$ \\
\hline $\begin{array}{l}\text { Signage/bench top } \\
\text { references }\end{array}$ & $\begin{array}{l}\text { - Laboratory signs and bench top reference for } \\
\text { equipment not pasted }\end{array}$ & $\begin{array}{l}\text { Provided the necessary lab signs, job aids and } \\
\text { advocate with hospital management to review the } \\
\text { policy of no wall posters }\end{array}$ \\
\hline Facility and safety & $\begin{array}{l}\text { - Waste not properly segregated and disposed. } \\
\text { - } \quad \text { Expired fire extinguisher, expired eye wash } \\
\text { - } \text { available } \\
\text { - } \quad \text { First-Aid box not available } \\
\text { - Hanging of electrical wire }\end{array}$ & $\begin{array}{ll}\text { - } & \text { Provided training on biological waste management } \\
\text { involving facilities cleaners } \\
\text { - } & \text { Provided sharp containers, colour-coded bins and } \\
& \text { liners } \\
\text { - } & \text { Refilled expired fire extinguishers and provided } \\
& \text { First Aid Box/Eye wash } \\
\text { - } & \text { Ensured focal person for PEP identified with } \\
\text { contact information accessible to all staff } \\
\text { - } \quad \text { Reviewed and updated safety policy } \\
\text { - Hanging electrical wires were repaired }\end{array}$ \\
\hline
\end{tabular}

HOD: Head of department, PEP: Post Exposure Prophylaxis, CAPA: Corrective Action and Preventive Action, LJ: Levey Jennings, SOPs: Standard Operating Procedures, EQC: External Quality Control, IQC: Internal Quality Control.

quality change per QE. Organization and personnel showed the highest improvements with a 32.2 percentage point change, while signage/bench top references had an 18.6 percentage point decline between Q1 and Q4 (Figure 1).

For the mean score of QEs across all facilities, statistically significant differences were found for the following QEs between quarters 1, 2, 3 and 4; documents and records, organization and personnel, internal and external quality control, inventory control system, and signage/bench top references $(\mathrm{p}<0.0001)$ (Table 4). The difference in scores across all four quarters were not statistically significant for equipment $(p=0.70)$ and facility and safety $(\mathrm{p}=0.10)$. However, a decreasing trend in scores was observed for signage/bench top reference.

Mean total score on all quality essentials was $63.34 \pm 9.77$ in quarter 1, $68.8 \pm 10.91$ in quarter 2, $72.59 \pm 8.02$ 


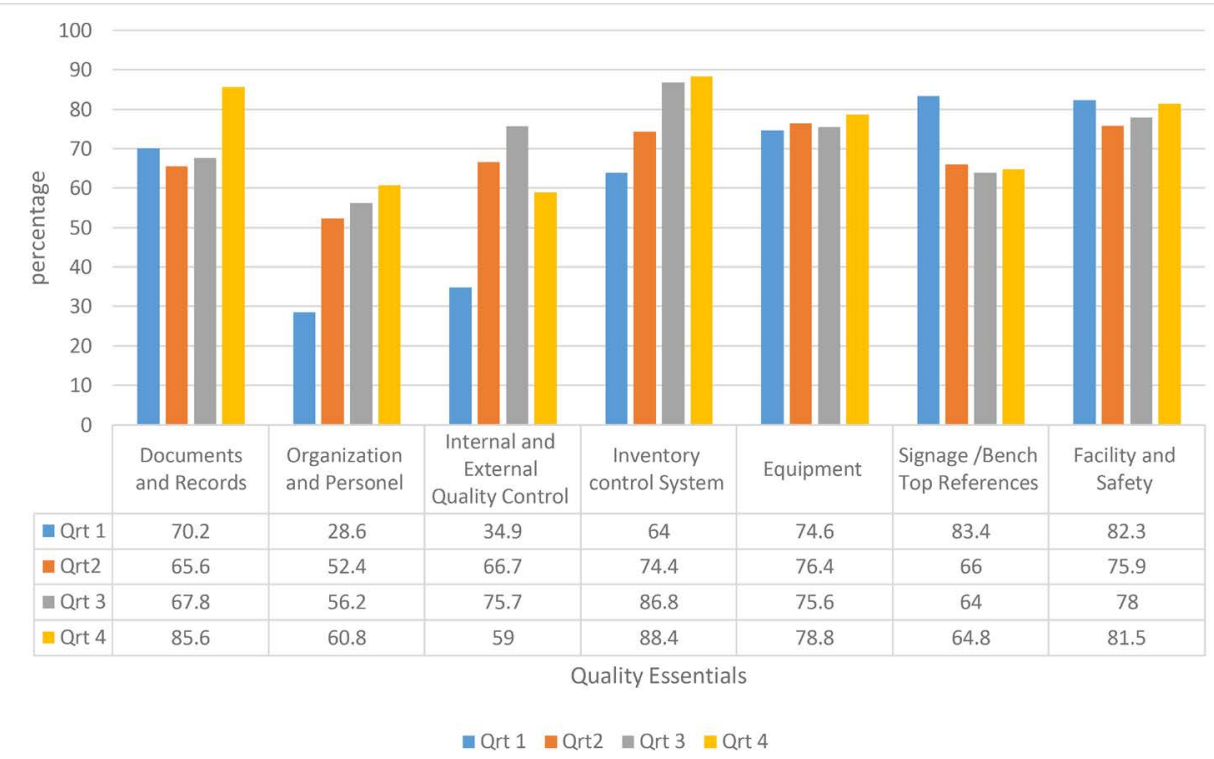

Qrt-Quarter.

Figure 1. Percentage scores for quality essentials, quarter 1 to quarter 4.

in quarter 3 and $72.72 \pm 9.16$ in quarter $4(\mathrm{p}<0.0001)$ (Table 4).

The total NCs cited for QI to Q4 were 185, 100, 78 and 64 respectively. Details and a follow through of the NCs cited in at least 10 facilities at the first audit is shown in Table 5. The QE internal and external quality control had the highest (66) NCs in Quarter (Q1) while facility and safety was the least. For all the QEs, the NCs steadily reduced form Q1-Q4 with the exception of Signage/bench top reference.

\section{Discussion}

Through quarterly audits and monitoring visits, we have been able to evaluate and report on changes in the quality status of 25 laboratories in the North West region of Nigeria over a year period. Although the findings showed that the total mean score on all QEs was highest in Q4 (72.72 \pm 9.16$)$, only 4 (16\%) facilities showed continuous improvement in quality performance over the one year period. However, quality management system implementation in most of these facilities is still suboptimal due to the fact that it is a new concept requiring more time and efforts to be entrenched in routine practice. Similarly, a 2013 report on laboratory assessment in Uganda showed that only $4.7 \%$ of 954 laboratories met or surpassed the lowest quality standard [15]. In addition, another 2013 report showed that 37 of 49 countries in sub-Saharan Africa had no laboratories meeting international quality standards [16].

Resource constraints, limited technical knowhow and time factor in terms of available certified auditors for technical assistance, necessitated the design of a modified version of the WHO/AFRO quality assessment checklist to attain minimum acceptable local quality standards [6] [11]. A general qualitative appraisal of the laboratory situations served as guidance on where to place emphases in adapting the WHO-AFRO checklist. Other studies in Uganda [15] and Nigeria [17] have reported using modified version of this checklist.

It is worth noting that none of the four facilities that had $80 \%$ and above in the overall mean score were among the first five facilities ranked based on point increase between Q1 and Q4 denoting significant improvement in quality standard. This highlights the fact that the most improved facility may still be down the quality ladder. Ideally, we should strive at having both better ranking and improvement in mean score over time. Significant number of the facilities required urgent intervention to address gaps and specific identified challenges. None of the tertiary facilities was among the top four good performing facilities in terms of improved performance between quarters or overall mean score. This was at variance with documented report of a study in Nigeria on HIV Testing and Counselling facilities where the upper tier (secondary) facilities were better than the lower tier (primary) in quality standards [17]. The marginal increase in three and decrease in seven facilities (Table 3) in quality improvement between Q4-Q1 can partly be attributed to staff transfer and attrition as reported 
Table 3. Facility ranking based on the difference in Q1 and Q4 score.

\begin{tabular}{|c|c|c|c|c|c|}
\hline Laboratory Name & State & Level of Care & $\begin{array}{l}\text { Q1 to Q4 } \\
\text { Percentage } \\
\text { Score }\end{array}$ & $\begin{array}{c}\text { Difference in Total Score } \\
\text { Q4-Q1 }\end{array}$ & Ranking \\
\hline Kachia GH, Kaduna & Kaduna & Secondary & 70.4 & 27 & $1^{\mathrm{st}}$ \\
\hline Wudil GH, Kano & Kano & Secondary & 69.4 & 23.5 & $2^{\text {nd }}$ \\
\hline Gumel GH, Jigawa & Jigawa & Secondary & 75.6 & 23.5 & $3^{\text {rd }}$ \\
\hline Illela GH, Sokoto & Sokoto & Secondary & 63.1 & 23.5 & $4^{\text {th }}$ \\
\hline Dogo Dagi GH, Sokoto & Sokoto & Secondary & 59.1 & 19.5 & $5^{\text {th }}$ \\
\hline $\begin{array}{c}\text { Sir Mohammed Sanusi Specialist Hospital, } \\
\text { Kano }\end{array}$ & Kano & Secondary & 80.3 & 18 & $6^{\text {th }}$ \\
\hline Hasiya Bayero Peadiatric Hospital, Kano & Kano & Secondary & 73.6 & 16 & $7^{\text {th }}$ \\
\hline Ikara GH, Kaduna & Kaduna & Secondary & 81.3 & 16 & $8^{\text {th }}$ \\
\hline ZongoKataf GH, Kaduna & Kaduna & Secondary & 60.4 & 14.5 & $9^{\text {th }}$ \\
\hline TalataMafara GH, Zamfara & Zamfara & Secondary & 65.6 & 14.5 & $10^{\text {th }}$ \\
\hline $\begin{array}{c}\text { Murtala Mohammed Specialist Hospital, } \\
\text { Kano }\end{array}$ & Kano & Secondary & 65.8 & 14 & $11^{\text {th }}$ \\
\hline FMC, Zamfara & Zamfara & Tertiary & 73.1 & 14 & $12^{\text {th }}$ \\
\hline Birnin Gwari GH, Kaduna & Kaduna & Secondary & 80.6 & 11.5 & $13^{\text {th }}$ \\
\hline Katsina GH, Katsina & Katsina & Secondary & 73.5 & 10.5 & $14^{\text {th }}$ \\
\hline Shinkafi GH, Zamfara & Zamfara & Secondary & 62.0 & 8 & $15^{\text {th }}$ \\
\hline Kaura Namoda GH, Zamfara & Zamfara & Secondary & 83.1 & 6 & $16^{\text {th }}$ \\
\hline Funtua GH, Katsina & Katsina & Secondary & 78.4 & 5.5 & $17^{\text {th }}$ \\
\hline Zuru GH, Kebbi & Kebbi & Secondary & 59.8 & 2.5 & $18^{\text {th }}$ \\
\hline Daura GH, Katsina & Katsina & Secondary & 62.7 & -1.5 & $19^{\text {th }}$ \\
\hline Sokoto Specialist Hospital, Sokoto & Sokoto & Secondary & 78.9 & -2 & $20^{\text {th }}$ \\
\hline Yauri GH, Kebbi & Kebbi & Secondary & 62.8 & -4.5 & $21^{\mathrm{st}}$ \\
\hline Tambuwal GH, Sokoto & Sokoto & Secondary & 69.5 & -5 & $22^{\text {nd }}$ \\
\hline Sir Yahaya Specialist Hospital, Kebbi & Kebbi & Secondary & 70.4 & -5 & $23^{\text {rd }}$ \\
\hline Dutsin Ma GH, Katsina & Katsina & Secondary & 72.8 & -6 & $24^{\text {th }}$ \\
\hline FMC, Kebbi & Kebbi & Tertiary & 75.1 & -9.5 & $25^{\text {th }}$ \\
\hline
\end{tabular}

GH: General Hospital, FMC: Federal Medical Center.

ported in the Lesotho laboratory accreditation implementation program [18]. This is more critical with the de parture of the head of departments like in Yauri GH, Daura GH and Dutsin Ma GH compounded with improper handing over or completed neglect of the process. Therefore new heads eventually takes over leadership roles without training or knowledge of quality system management implementation. Furthermore, supportive supervision was less frequent especially in Kebbi, Sokoto and Zamfara states where a few facilities (Illela GH, Yauri GH, Zuru, GH Shinkafi GH and KauraNamoda GH) are located in hard to reach areas. For effective resource management, integrated supportive supervisory site visit to these three states along the same axis were carried out with other program team members. On the other hand states such as Kano, Kaduna, Katsina and Jigawa benefited from more frequent and laboratory focused supportive supervisory visits and mentorship. However, as part of FHI360 effort to build capacity, ensure ownership and sustainability, the government of Nigeria (GON) staff who are State Implementation Team (SIT) focal persons for laboratory in Kebbi, Sokoto and Zamfara states mostly carried out the assessment and other laboratory related supervisions. Additionally, about half (48\%) of audited facilities have only one laboratory scientist and one facility (Illela GH) had only laboratory technicians and coping with documentation and record keeping remain a challenge. Thus availability of qualified, teachable 
Table 4. Mean score of quality essentials across all facilities from Quarters 1, 2, 3 and 4.

\begin{tabular}{cccccc}
\hline Quality Essentials & Q1 & Q2 & Q3 & Q4 & p Value \\
\hline Documents and Records & $7.02 \pm 2.19$ & $6.56 \pm 1.63$ & $6.78 \pm 1.54$ & $8.56 \pm 1.63$ & $<0.0001$ \\
Organization and Personnel & $2.86 \pm 2.68$ & $5.24 \pm 3.05$ & $5.6 \pm 2.81$ & $6.08 \pm 2.49$ & $<0.0001$ \\
Internal/External Quality Control & $7.32 \pm 4.18$ & $14 \pm 6.91$ & $15.9 \pm 5.85$ & $12.4 \pm 4.51$ & $<0.0001$ \\
Inventory Control System & $6.4 \pm 2.43$ & $7.44 \pm 2.10$ & $8.68 \pm 1.41$ & $8.84 \pm 1.37$ & $<0.0001$ \\
Equipment & $7.46 \pm 1.42$ & $7.64 \pm 1.66$ & $7.56 \pm 1.24$ & $7.88 \pm 1.34$ & 0.6963 \\
Signage/bench top reference & $14.18 \pm 2.00$ & $11.22 \pm 3.99$ & $10.88 \pm 2.66$ & $11.02 \pm 3.03$ & $<0.0001$ \\
Facility and Safety & $18.1 \pm 3.15$ & $16.7 \pm 2.57$ & $17.16 \pm 2.88$ & $17.94 \pm 1.59$ & 0.1013 \\
Total Score & $\mathbf{6 3 . 3 4} \pm \mathbf{9 . 7 7}$ & $\mathbf{6 8 . 8} \pm \mathbf{1 0 . 9 1}$ & $\mathbf{7 2 . 5 9} \pm \mathbf{8 . 0 2}$ & $\mathbf{7 2 . 7 2 \pm \mathbf { 9 . 1 6 }}$ & $<\mathbf{0 . 0 0 0 1}$ \\
\hline
\end{tabular}

Q1: Quarter 1, Q2: Quarter 2, Q3: Quarter 3, Q4: Quarter 4. p-value is significant when p $<0.05$.

Table 5. Trend in non-conformities cited in at least 10 facilities at first audit.

\begin{tabular}{|c|c|c|c|c|}
\hline \multirow{2}{*}{ Quality essentials and cited non-conformities } & \multicolumn{4}{|c|}{ Number of facilities with non-conformities } \\
\hline & Q1 & Q2 & Q3 & Q4 \\
\hline \multicolumn{5}{|l|}{ Documents and records } \\
\hline SOPs not signed by relevant Lab personnel & 12 & 10 & 8 & 0 \\
\hline \multicolumn{5}{|l|}{ Organization and personnel } \\
\hline No organogram & 10 & 7 & 5 & 3 \\
\hline $\begin{array}{l}\text { No staff folders, job description, certificates of training and other relevant } \\
\text { documents not found in staff folders }\end{array}$ & 11 & 9 & 5 & 6 \\
\hline \multicolumn{5}{|l|}{ Internal and external quality control } \\
\hline No internal quality control records and L-J chart not plotted & 20 & 16 & 12 & 10 \\
\hline Non-participation in at least one External quality control CD4 count & 20 & 1 & 0 & 0 \\
\hline Internal audit was not conducted by facility quality officer & 16 & 13 & 10 & 9 \\
\hline $\begin{array}{c}\text { No CAPA documentation of poor external quality control and internal quality } \\
\text { control performance }\end{array}$ & 10 & 5 & 4 & 0 \\
\hline \multicolumn{5}{|l|}{ Inventory control system } \\
\hline Tally cards not updated for lab reagents and consumables & 14 & 6 & 4 & 3 \\
\hline Ambient and refrigerating temperature not monitored & 14 & 0 & 2 & 4 \\
\hline \multicolumn{5}{|l|}{ Equipment } \\
\hline Operators' equipment daily maintenance charts not updated and reviewed & 19 & 6 & 6 & 5 \\
\hline \multicolumn{5}{|l|}{ Facilities and safety } \\
\hline PEP guideline with designated contact person not available & 10 & 5 & 2 & 4 \\
\hline \multicolumn{5}{|l|}{ Signage/bench top references } \\
\hline No food, no drink or no food, no drink picture format not t displayed & 10 & 8 & 10 & 9 \\
\hline Unauthorized person not allowed sign not displayed & 11 & 7 & 10 & 9 \\
\hline No separate sample collection/phlebotomy area & 10 & 7 & 5 & 5 \\
\hline
\end{tabular}

Q1: Quarter 1, Q2: Quarter 2, Q3: Quarter 3, Q4: Quarter 4, PEP: Post Exposure Prophylaxis, CAPA: Corrective Action and Preventive Action LJ: Levey Jennings, SOPs: Standard Operating Procedures. 
and dedicated staff in some cases was a challenge.

Overall, there was an improvement in the quality standards as judged by QE mean score, QEs percentage and the trend of NCs over the quarters with the exception of signage/bench top references. The poor performance on signage/bench top references is partly due to policies in some facilities that prohibits wall posters in the laboratory. Significant improvement was seen in some of the QEs like document and records and inventory control system. This was, partly because even before the introduction of this structured internal audits, reports on completion of laboratory monthly summary forms was a key laboratory performance indicator monitored for all facilities. Information on commodity utilization and stock balance is mandatory for resupply of ART commodities, thus documents pertaining to the inventory control system like the combined report requisition and issued from (CRIFF) as well as Tally cards were mostly available. Furthermore, stock status is regularly verified on-site and any discrepancies promptly addressed to avoid stock outs, thus keeping lab staff conscious of this QE. The common NCs encountered in this study (Table 5) are not unique to these laboratories as similar NCs were reported during the assessments of medical laboratories in Lesotho [18] and Hong Kong [19]. In our study, NCs was more common in the area of internal and external quality control. This is mainly due to poor documentation of internal quality control practice and information on external quality control performance review was uncommon. A study by Chizizi et al. in Malawi reported the common absence of external quality assurance systems [20] in testing facilities assessed. The decrease in number of NCs over the period substantiated that audits and reviews contributed to quality improvement.

Some general challenges to smooth implementation of QM program include: Lack of required training and skills on quality management systems, insufficient number of laboratory staff available at sites, attrition, frequent transfer and more importantly poor staff attitude prohibits smooth and sustained implementation of QM programs. Some laboratory staff still do not realize the usefulness of quality management systems and consider these requirements as unnecessary extra burden. The complaint of extra work and no monetary incentive are the most common excuses in most facilities. Limited resources remain another major challenge. For example, in 2012 among all the expected trainings to cover laboratory quality management, only four trainings; (equipment operations, quality management system, good clinical laboratory practice and sample collection and sample referral) could be accommodated within the project budget for at most two laboratory staff per facility. Thus we resort to on-site step-down trainings by facility staff. The scope and quality of these steps down training could not be ascertained as putting the concept to practice has always been an uphill task. Furthermore, when financial resource is involved to redress quality gaps like servicing fire extinguishers and refrigerator, transfer of specimen, printing of documents, travelling for mentoring and supervision etc., there is much delay. This is mostly due to weak financial management systems within the facilities and the state ministries. However, FHI360 is working in collaboration with Deloitte Consulting, Inc. USA to provide capacity building in organizational and financial management to ensure better governance, ownership and sustainability of the program.

With this simple and easy to administer tool, we can quickly determine the minimum quality standard and evaluate output of technical support overtime. Furthermore, based on performance in these audits coupled with facility commitment and staff attitude, we have been able to make informed decision on facilities to present for the WHO/AFRO accreditation rollout. Namely, Hasiyya Bayero Pediatrics Hospital Kano, Federal Medical Center, Gusua-Zamfara, Sokoto Specialist Hospital Sokoto and Sir Mohammed Sanusis Specialist Hospital Kano. These results support the usefulness of a fit-for-purpose checklist and the benefit of the internal audit programs for assessing and monitoring clinical laboratories in our setting to ascertain if minimum level of quality standards is in place, while striving toward accreditation preparedness through SLIPTA WHO/AFRO and other international standards.

In as much as the overall improvement was minimal, the exercise was crucial for identifying weak points in laboratory activities and to allow for tailored interventions and targeted plans to match the limited resources and knowhow. Overall, more is still required to be done in quality management system implementation in our laboratories. The concept has not yet become a culture in these laboratories especially with the series of documentation and record keeping required coupled with human resources and attitudinal challenges. Similarly, some studies have reported that laboratory staff view accreditation process as being over bureaucratic [21] [22] and staff attitude [23] [24] possess a lot of challenge to implement quality management systems.

Some limitations of this study include; Non uniform assessment of performance in external quality assurance (EQA) in the facilities. Some facilities were at a disadvantage as they were not registered for other EQA other than CD4+, and registration of facilities for EQA was not at same time. Therefore, incomplete data specific to this QE was unavoidable within the audit period. Our adapted fit for purpose checklist did not allow for "Star 
1-5" incremental level rating like in WHO-AFRO SLIPTA checklist [8]. Thus, it is difficult to match performance with other standards. However, with much caution, a score of over $80 \%$ in our assessment could likely translate to at least "Star 1" rating. Due to security challenges, quarter four audit assessment was conducted in about $80 \%$ of facilities by SIT laboratory focal person having limited experience in QMS and structured audits. Hence Q4 results need to be interpreted with more caution, even though it was reviewed by FHI360 laboratory technical staff. The ranking of sites based on Q4-Q1 difference (most improved site) does not directly relate to the highest/ best site in terms of quality standing as judged by average mean score. Thus a combination of both ranking and average mean performance is a better approach to assess overall quality improvement. However, this analysis to rank sites is very critical in our program as it allows us to rate the level of commitment and provides guidance in the choice of facilities to target in piloting special quality improvement initiatives. The frequency (quarterly) of the audits may not have allowed facility staff enough time to assimilate and understand the quality concept. This current audit focuses only on ART laboratory and does not reflect the quality of services offered in the facility main laboratory.

\section{Recommendations and Conclusions}

There is a need to institute a policy of periodic staff training, refresher trainings and competency assessment in facilities. Incorporating quality management system in laboratory training curriculum at universities and institutes of medical laboratory science where laboratory technicians and assistants are being trained is also needful. In-service training for laboratory professional on QMS in order to address knowledge gaps in quality management system should also be instituted. Respective State Ministries of Health and Health Management Boards should address training gaps by taking responsibility for training more laboratory personnel when implementing partner program budgets accommodates only a limited number of personnel, as part of sustainability and ownership strategy.

Temporal deployment of laboratory staff that are trained and skillful in quality management systems to other facilities to provide, peer mentorship and conduct on-site training for incoming heads of laboratories should be encouraged.

Advocacy to State Ministries of Health/ Hospital Management Board to minimize staff transfers should be carried out. In addition, work load analysis should be carried out for all facilities to determine workforce related issues and deploy laboratory staff to sites with human resource gaps to address excess work load syndrome.

Quality teams should be formed with clear term of reference and quality and safety managers different from the laboratory head should be appointed. Special motivational packages like periodic awards for excellent performance, travel awards to serve as peer mentors or conference support should be introduced. Quality improvement projects should be initiated and monitored across laboratories through quality indicators.

Proficiency testing (PT) should be extended to more facilities and cheaper PT options such as Medical Laboratory Sciences Council of Nigeria (MLSCN) PT scheme and PT alternatives like peer/inter laboratory comparison should be explored. The capacity of local biomedical engineers on equipment maintenance and repair should be strengthened and the culture of planned preventive maintenance enforced.

Audits and trainings should go beyond the ART laboratory applying an integrated approach [25] to minimize manpower shortages, knowledge gaps and encourage staff rotation. Customer satisfaction survey involving other technical collaborators with the laboratory team and patients should be instituted periodically.

We recorded improvement in most quality essentials substantiating the benefits of audits, review and follow up. This exercise has been used as a platform for informed decision on selection of facilities towards WHO/AFRO accreditation roll-out. More attention is required to improve on the QEs like internal and external quality control and signage /bench top references in our settings. Overall these laboratories still lack the quality standard to benchmark minimal quality requirements like "Star-1" rating of the WHO/AFRO accreditation scheme [8]. Continuous mentoring and monitoring of laboratories by knowledgeable and skillful laboratory personnel, commitment from facility technical team, management support at facility and state level is a key to improvement in laboratory quality standards. This approach can surely provide reference for other countries.

\section{Authors Contributions}

Conceived and designed of experiment: FEJ, TNY, HAM; Performed the experiment: FEJ, TNY, analyzed the data: OA, HAM, FEJ, ORN-M, KT; wrote the paper: FEJ, TNY, HAM; reviewed the manuscript: FEJ, TNY, HAM, ORN-M, OA, KT. 


\section{Ethical Approval}

FHI360 Office of International Research Ethics (OIRE), North Carolina, USA, approved the study (IRB No. 537314-1).

\section{Financial Disclosure Statement}

Support for this study was provided by FHI360 Nigeria with funds from the U.S. President's Emergency Plan for AIDS Relief (PEPFAR) through US Agency for International Development (USAID)

\section{Competing Interest}

The authors have declared no competing interests. The views expressed herein are those of the authors and do not necessarily reflect those of FHI360.

\section{Acknowledgements}

Our sincere appreciation also goes to all stakeholders in respective state ministry of health including laboratory staffs of all Hospitals in North West of Nigeria where this study was conducted.

\section{References}

[1] Carraro, P. and Plebani, M. (2007) Errors in a Stat Laboratory: Types and Frequencies 10 Years Later. Clinical Chemistry, 53, 1338-1342. http://dx.doi.org/10.1373/clinchem.2007.088344

[2] Abimiku, A.G. (2009) Building Laboratory Infrastructure to Support Scale-Up of HIV/AIDS Treatment, Care, and Prevention: In-Country Experience. American Journal of Clinical Pathology, 131, 875-886. http://dx.doi.org/10.1309/AJCPELMG6GX6RQSM

[3] Audu, R.A., et al. (2011) Experience of Quality Management System in a Clinical Laboratory in Nigeria. African Journal of Laboratory Medicine, 1, 1-5. http://dx.doi.org/10.4102/ajlm.v1i1.18

[4] Guindo, M.A., et al. (2012) Promoting Good Clinical Laboratory Practices and Laboratory Accreditation to Support Clinical Trials in Sub-Saharan Africa. The American Journal of Tropical Medicine and Hygiene, 86, 573-579. http://dx.doi.org/10.4269/ajtmh.2012.11-0691

[5] Zeh, C.E., Inzaule, S.C., Magero, V.O., Thomas, T.K., Laserson, K.F., Hart, C.E. and Nkengasong, J.N. (2010) Field Experience in Implementing ISO 15189 in Kisumu, Kenya. American Journal of Clinical Pathology, 134, 410-418. http://dx.doi.org/10.1309/AJCPZIRKDUS5LK2D

[6] Erasmus, R.T. and Zemlin, A.E. (2009) Clinical Audit in the Laboratory. Journal of Clinical Pathology, 62, 593-597. http://dx.doi.org/10.1136/jcp.2008.056929

[7] (2009) Comprehensive Accreditation Manual for Pathology and Laboratory Services. Joint Commission, Oakbrook.

[8] Gershy-Damet, G.-M., et al. (2010) The World Health Organization African Region Laboratory Accreditation Process: Improving the Quality of Laboratory Systems in the African Region. American Journal of Clinical Pathology, 134, 393-400. http://dx.doi.org/10.1309/AJCPTUUC2V1WJQBM

[9] Yao, K., McKinney, B., Murphy, A., Rotz, P., Wafula, W., Sendagire, H., Okui, S. and Nkengasong, J.N. (2010) Improving Quality Management Systems of Laboratories in Developing Countries: An Innovative Training Approach to Accelerate Laboratory Accreditation. American Journal of Clinical Pathology, 134, 401-409. http://dx.doi.org/10.1309/AJCPNBBL53FWUIQJ

[10] International Organisation for Standardisation (2012) ISO 15189:2012: Medical Laboratories Requirements for Quality and Competence. International Organisation for Standardisation, Geneva. http://www.iso.org

[11] Datema, T.A.M., Oskam, L. and Klatser, P.R. (2011) Review and Comparison of Quality Standards, Guidelines and Regulations for Laboratories. African Journal of Laboratory Medicine, 1, 1-7. http://dx.doi.org/10.4102/ajlm.v1i1.3

[12] Wattanasri, N., Manoroma, W. and Viriyayudhagorn, S. (2010) Laboratory Accreditation in Thailand: A Systemic Approach. American Journal of Clinical Pathology, 134, 534-540. http://dx.doi.org/10.1309/AJCPZYY19WMKMAZT

[13] Nordling, L. (2009) African Disease Labs to Get Health Check. Nature, Published Online. http://dx.doi.org/10.1038/news.2009.735

[14] World Health Organization (2010) WHO Guide for the Stepwise Laboratory Improvement Process towards Accreditation in the African Region (Checklist). WHO, Geneva, 1-60.

[15] Elbireer, A.M., Jackson, J.B., Sendagire, H., Opio, A., Bagenda, D. and Amukele, T.K. (2013) The Good, the Bad, and 
the Unknown: Quality of Clinical Laboratories in Kampala, Uganda. PLoS ONE, 8, e64661. http://dx.doi.org/10.1371/journal.pone.0064661

[16] Schroeder, L.F. and Amukele, T. (2014) Medical Laboratories in Sub-Saharan Africa That Meet International Quality Standards. American Journal of Clinical Pathology, 141, 791-795. http://dx.doi.org/10.1309/AJCPQ5KTKAGSSCFN

[17] Asamole-Osuocha, C., Mbah, H., Cartier, S., Ojo, E., Badru, T., Ibrahim, M., Oka, I., Egwa, E. and Chabikuli, O. (2014) External Quality Assessment: On-Site Evaluation of HIV Testing and Counselling Sites in Nigeria. Journal of AIDS and HIV Research, 6, 97-103.

[18] Mothabeng, D., Maruta, T., Lebina, M. and Lewis, K. (2012) Strengthening Laboratory Management towards Accreditation: The Lesotho Experience. African Journal of Laboratory Medicine, 1, 1-2. http://dx.doi.org/10.4102/ajlm.v1i1.9

[19] Ho, B. and Kong, H. (2012) The Most Common Nonconformities Encountered during the Assessments of Medical Laboratories in Hong Kong Using ISO 15189 as Accreditation Criteria. Biochemia Medica, 22, 247-257. http://dx.doi.org/10.11613/BM.2012.027

[20] Chimzizi, R.B., Harries, A.D., Manda, E., Khonyongwa, A., Killam, W.P. and Salaniponi, F.M. (2005) The Use of a Monitoring Tool to Assess Counselling and HIV Testing in the Public Health Sector in Malawi. Tropical Doctor, 35, 72-75. http://dx.doi.org/10.1258/0049475054037020

[21] Gough, L.A. and Reynolds, T.M. (2000) Is Clinical Pathology Accreditation Worth It? A Survey of CPA-Accredited Laboratories. Clinical Performance and Quality Healthcare, 8, 195-201. http://dx.doi.org/10.1108/14664100020361746

[22] Alkhenizan, A. and Shaw, C. (2012) The Attitude of Health Care Professionals towards Accreditation: A Systematic Review of the Literature. Journal of Family and Community Medicine, 19, 74-80. http://dx.doi.org/10.4103/2230-8229.98281

[23] Agyeman-Duah, J., Theurer, A., Munthali, C., Alide, N. and Neuhann, F. (2014) Understanding the Barriers to Setting up a Healthcare Quality Improvement Process in Resource-Limited Settings: A Situational Analysis at the Medical Department of Kamuzu Central Hospital in Lilongwe, Malawi. BMC Health Services Research, 14, 1. http://dx.doi.org/10.1186/1472-6963-14-1

[24] Latham, T., Malomboza, O., Nyirenda, L., Ashford, P., Emmanuel, J., M’baya, B. and Bates, I. (2012) Quality in Practice: Implementation of Hospital Guidelines for Patient Identification in Malawi. International Journal for Quality in Health Care, 24, 626-633. http://dx.doi.org/10.1093/intqhc/mzs038

[25] Mbah, H., Negedu-Momoh, O.R., Adedokun, O. and Anibbe, P. (2014) Implementing and Measuring the Level of Laboratory Service Integration in a Program Setting in Nigeria. PLoS ONE, 9, e107277.

http://dx.doi.org/10.1371/journal.pone.0107277 
Scientific Research Publishing (SCIRP) is one of the largest Open Access journal publishers. It is currently publishing more than 200 open access, online, peer-reviewed journals covering a wide range of academic disciplines. SCIRP serves the worldwide academic communities and contributes to the progress and application of science with its publication.

Other selected journals from SCIRP are listed as below. Submit your manuscript to us via either submit@scirp.org or Online Submission Portal.
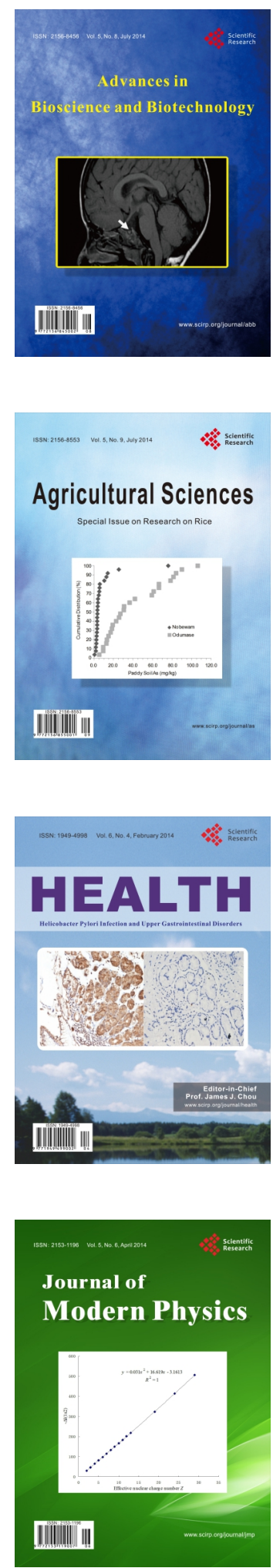
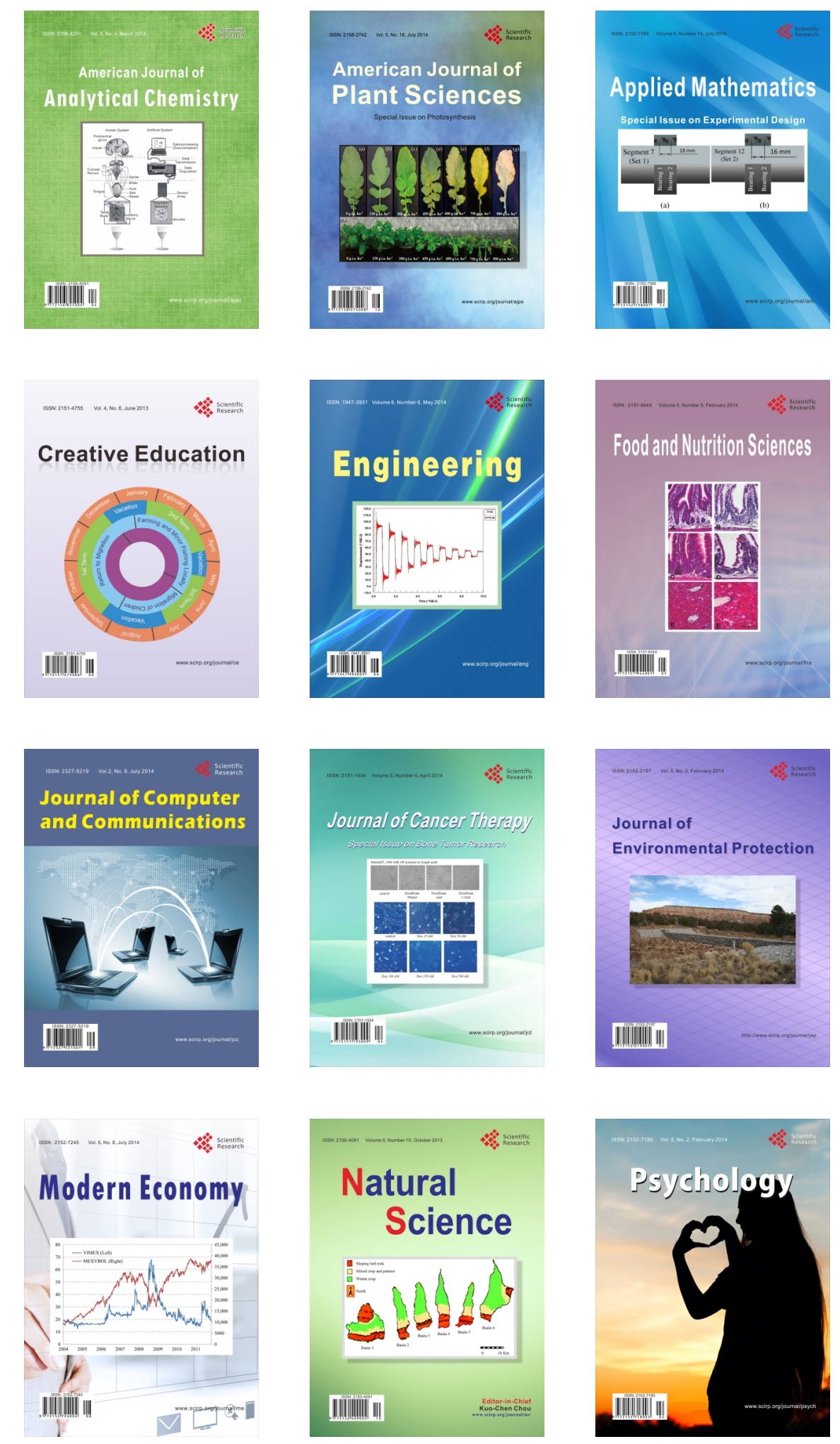